\title{
Cavity ring-down spectroscopy sensor for detection of hydrogen chloride
}

\author{
C. L. Hagen ${ }^{1, *}$, B. C. Lee ${ }^{2}$, I. S. Franka ${ }^{1}$, J. L. Rath ${ }^{1}$, T. C. VandenBoer ${ }^{4, *}$, J. M. Roberts ${ }^{3}$, S. S. Brown ${ }^{3}$, and \\ A. P. Yalin ${ }^{1}$ \\ ${ }^{1}$ Department of Mechanical Engineering, Colorado State University, Fort Collins, Colorado, USA \\ ${ }^{2}$ Department of Physics, Colorado State University, Fort Collins, Colorado, USA \\ ${ }^{3}$ NOAA Earth System Research Laboratory, Boulder, Colorado, USA \\ ${ }^{4}$ Department of Chemistry, Memorial University of Newfoundland, St. Johns, Newfoundland, Canada \\ *now at: Oregon State University-Cascades, Bend, Oregon, USA \\ ** now at: Department of Chemistry, University of Toronto, Toronto, Ontario, Canada
}

Correspondence to: A. P. Yalin (ayalin@engr.colostate.edu)

Received: 3 July 2013 - Published in Atmos. Meas. Tech. Discuss.: 6 August 2013

Revised: 19 December 2013 - Accepted: 19 December 2013 - Published: 3 February 2014

\begin{abstract}
A laser-based cavity ring-down spectroscopy (CRDS) sensor for measurement of hydrogen chloride ( $\mathrm{HCl})$ has been developed and characterized. The instrument uses light from a distributed-feedback diode laser at $1742 \mathrm{~nm}$ coupled to a high finesse optical cavity to make sensitive and quantifiable concentration measurements of $\mathrm{HCl}$ based on optical absorption. The instrument has a $(1 \sigma)$ limit of detection of $<20 \mathrm{pptv}$ in $1 \mathrm{~min}$ and has high specificity to $\mathrm{HCl}$. The measurement response time to changes in input $\mathrm{HCl}$ concentration is $<15 \mathrm{~s}$. Validation studies with a previously calibrated permeation tube setup show an accuracy of better than $10 \%$. The CRDS sensor was preliminarily tested in the field with two other $\mathrm{HCl}$ instruments (mist chamber and chemical ionization mass spectrometry), all of which were in broad agreement. The mist chamber and CRDS sensors both showed a 400 pptv plume within 50 pptv agreement. The sensor also allows simultaneous sensitive measurements of water and methane, and minimal hardware modification would allow detection of other near-infrared absorbers.
\end{abstract}

\section{Introduction}

\subsection{Role of $\mathrm{HCl}$ in the atmosphere}

Chemical reactions involving halogen radical species, such as chlorine and bromine atoms and their oxides, significantly influence the composition of the Earth's atmosphere. These species also play important roles in many atmospheric processes including the formation and destruction of ozone. In remote regions of the troposphere, such as the polar boundary layer, halogen species are thought to contribute to the destruction of ozone (Vogt et al., 1996; Simpson et al., 2007). The ozone depletion, along with formation of new oxidizing agents, may ultimately lead to a change in the dominant oxidizing agents. In contrast, in polluted marine boundary layers and in populated coastal regions, halogen species can contribute to ozone formation (Tanaka et al., 2000; Knipping and Dabdub, 2003). Other atmospheric processes in the marine boundary layer, such as the oxidation of methane (Platt et al., 2004; Allan et al., 2007) and larger hydrocarbons (Jobson et al., 1994), can also be influenced by halogens. The chlorine radical also plays a key role in ozone destruction within the upper stratosphere (Solomon, 1999).

Hydrogen chloride, $\mathrm{HCl}$, is an important reservoir species for active halogens. Studies of composite chlorine emissions indicate that $\mathrm{HCl}$ is the dominant gas-phase contributor to the overall chlorine inventory in the lower atmosphere (Graedel and Keene, 1995; Keene et al., 1999). The principal source of $\mathrm{HCl}$ in the lower atmosphere is thought to be from acid displacement chemistry on sea spray aerosols in the marine boundary layer, though the extent of the contribution from anthropogenic activity, such as coal burning, is not well understood (McCulloch et al., 1999). Chloride present in 
sea-salt aerosol generated by wind stress at the ocean surface is converted to $\mathrm{HCl}$ by acid-displacement reactions (Keene et al., 2007; Pszenny et al., 2004) and references therein. Typical $\mathrm{HCl}$ concentrations in remote marine environments span from tens to hundreds of parts per trillion (Kim et al., 2008), while reaching levels of several parts per billion in coastal urban areas (Maben et al., 1995; Keene et al., 2007). In the upper atmosphere ( $>\sim 40 \mathrm{~km}), \mathrm{HCl}$ is thought to account for more than $90 \%$ of the total chlorine inventory (Achard et al., 1997). However, estimates of $\mathrm{HCl}$ production vary considerably and existing measurements are limited. From an industrial perspective, high-temperature chlorine corrosion via $\mathrm{HCl}$ can be a costly problem for combustion and gasification plants (Bjoroey et al., 1996). There remains a strong need for improved measurement techniques for $\mathrm{HCl}$, as we address in the present contribution.

\subsection{Methods for $\mathrm{HCl}$ detection}

The understanding of sources and sinks of $\mathrm{HCl}$, as well as the role of $\mathrm{HCl}$ in proposed chemical mechanisms, requires suitable $\mathrm{HCl}$ measurement techniques with sufficient accuracy, sensitivity, specificity, and time-response. Currently, the available instruments for such studies are rather limited. The original methods for such studies involved bulk sampling with off-line determination of $\mathrm{HCl}$. One method was to sample gas-phase $\mathrm{HCl}$ into a solution using a mist chamber collector and to analyze the solution by high resolution ion chromatography (e.g., Keene et al., 1993; Scheuer et al., 2003). The method is attractive owing to its relative simplicity and reliability, but limitations include relatively low time resolution (typically tens of minutes or more) and potential interfering contributions from other active chlorine species, such as $\mathrm{ClNO}_{2}$, so the measurement is often referred to as $\mathrm{HCl}^{*}$ (Keene et al., 1993, 2007).

Another method for $\mathrm{HCl}$ detection is chemical ionization mass spectrometry (CIMS) (Roberts et al., 2010; Kim et al., 2008; Veres et al., 2008). The CIMS instruments allow rapid and sensitive detection of species and are amenable to both ground based and aircraft deployments (Veres et al., 2008). A potential limitation of these techniques is their specificity which depends on the details of the ion chemistry scheme. For example, Marcy et al. (2004) have reported interference from water vapor. The CIMS systems also require periodic zeroing and calibration. In addition, the need for a sensitive mass spectrometer significantly increases the cost of the technique as compared to optical approaches.

Optical absorption based measurements of $\mathrm{HCl}$ using infrared laser sources are also possible. By selecting an absorption line of the target species, i.e., $\mathrm{H}^{35} \mathrm{Cl}$, which does not have nearby interferences from other atmospheric constituents, optical measurements are species specific. Past work has employed tunable diode lasers in a multi-pass Herriot cell for $\mathrm{HCl}$ detection (Webster et al., 1994; Scott et al., 1999). The system was sensitive, species-specific, allowed rapid-time response and was amenable to airborne deployment. In order to access the strongest fundamental vibrational band, the system employed lead salt lasers at $3.4 \mu \mathrm{m}$ paired with mercury-cadmium-telluride (MCT) detectors, both of which required liquid nitrogen $\left(\mathrm{LN}_{2}\right)$ cooling.

The present instrument seeks to capitalize on advantages of optical absorption approaches, but employs a nearinfrared (NIR) diode laser at $1.74 \mu \mathrm{m}$. Use of NIR sources with indium-gallium-arsenide (InGaAs) detectors obviates the need for $\mathrm{LN}_{2}$ cooling thereby providing an important practical advantage. Further, the smaller cell volume possible in CRDS versus Herriot cells means our CRDS system uses a flow rate more than 10 times smaller than past Herriot cell work, allowing use of smaller and lower power vacuum pumps. In order to attain high detection sensitivity at $1.74 \mu \mathrm{m}$ (probing the weaker 2-0 vibrational band), continuous-wave cavity ring-down spectroscopy (cw-CRDS) is employed to achieve path lengths significantly longer than those from conventional multi-pass cells. The sensor is constructed from robust, readily available, and relatively inexpensive NIR laser sources and components (similar to those used in the telecom industry), which can operate unattended for years. Due to the inherently quantifiable nature of CRDS, the only required calibration is that of the relative laser frequency using an etalon, as described in Sect. 2. The overall versatility and specificity of this approach makes it attractive for $\mathrm{HCl}$ detection in the troposphere allowing, for example, comparisons against existing instruments which measure sums of active chlorine compounds. Additionally, the CRDS technique offers great potential for a very small and low power consumption instrument.

Recently, commercial CRDS $\mathrm{HCl}$ sensors have become available from Tiger Optics (Tig, 2013) and Los Gatos Research (LGR, 2013). Their design and operational details are not available in the open literature. The power draw, size, and weight of the above instruments are available on their respective websites. These parameters vary depending on which model is selected. Our instrument is currently a laboratory model and is in the process of being miniaturized into a more compact field instrument. We anticipate achieving similar weight and power to the commercial ones, with the exception of possibly the power draw. The main difference is that in order to achieve relatively fast time response $(<\sim 15 \mathrm{~s})$ our system employs high cavity flow rates, and therefore high pump speeds. In contrast, the available commercial instruments have relatively slow time response (an $80 \%$ response time of $2 \mathrm{~min}$ for the Tiger Optics instrument and a $10-90 \%$ time of $5 \mathrm{~min}$ for the Los Gatos Research instrument) and may not require such flow rates. If we compare our system against off-axis type cavity enhanced systems, then the smaller volume of our cavity means we can achieve a given cavity refill time with a lower pump speed. Additionally, the limits of detection of the presented instrument can be compared to the commercially available instruments. The Tiger Optics i-2000 $\mathrm{HCl}$ reports a $1 \sigma$ limit of detection of 
$250 \mathrm{pptv}$ (scaled from their quoted $3 \sigma, 750 \mathrm{pptv}$ value). The $80 \%$ response time is $2 \mathrm{~min}$, and is presumably the integration time for the above sensitivity. The Los Gatos Research $\mathrm{HCl}$ Analyzer reports a $100 \mathrm{~s} 1 \sigma$ sensitivity of $200 \mathrm{pptv}$. The $10 \%-90 \%$ response time is $5 \mathrm{~min}$. Our instrument compares very favorably with a $1 \mathrm{~min}, 1 \sigma$ sensitivity of $<20 \mathrm{pptv}$ and a $10 \%-90 \%$ response time of $<\sim 15 \mathrm{~s}$.

The layout of the remainder of the paper is as follows. Section 2 provides a description of the $\mathrm{HCl}$ CRDS sensor, including spectral simulation, hardware configuration, and operating details. Section 3 discusses instrument performance including characterizations of sensitivity and time response, validation studies with a calibrated permeation tube, and initial field deployment in parallel with two other instruments. The instrument performance specifications are contrasted against those of the aforementioned Herriot cell approach. Possible improvements to the sensor are also discussed. Finally, conclusions are presented in Sect. 4.

\section{Instrument description}

CRDS is an ultra-sensitive laser-based absorption technique, which may be used to measure trace species in the gas phase (Busch and Busch, 1999; Berden et al., 2000; Berden and Engeln, 2009; Gagliardi and Loock, 2014). The technique is seeing growing use in a range of fields including combustion diagnostics, plasma diagnostics, basic spectroscopic studies, and atmospheric trace gas detection. In the cw-CRDS technique, a high-finesse optical cavity is pumped with a continuous-wave (cw) single-mode narrow-linewidth laser (Lehmann, 1996; Romanini et al., 1997; He and Orr, 2002; Dudek et al., 2003). In a typical setup, the laser is scanned over a spectral line of the analyte, as the laser frequency overlaps with a resonance of the static cavity, significant intracavity power is built up. A piezoelectric transducer can also be used to achieve spectral overlap between the cavity and the laser, though that approach is not used here. Once such a resonance is detected with a photodetector placed after the cavity, an acousto-optic modulator is triggered to quickly extinguish the incoming laser beam. The same photodetector measures the subsequent exponential decay of light leaking out from the cavity, termed a ring down. The time constant of the ring down gives the total loss within the cavity. When the laser is tuned to resonance with the analyte, there will be additional loss, causing a faster decay (ring down). Using known line strength parameters for the specific spectral line, and the change in ring-down time, the species concentration can be calculated. The details of this procedure will be given later in this section.

The specific design of a spectroscopic instrument for absorption measurements is guided by the location and strength of the targeted absorption feature. For our instrument, the $\mathrm{R}(3) \mathrm{H}^{35} \mathrm{Cl}$ line of the (2-0) absorption band (see Fig. 1, Rothman et al., 2013) was chosen due to its relatively high

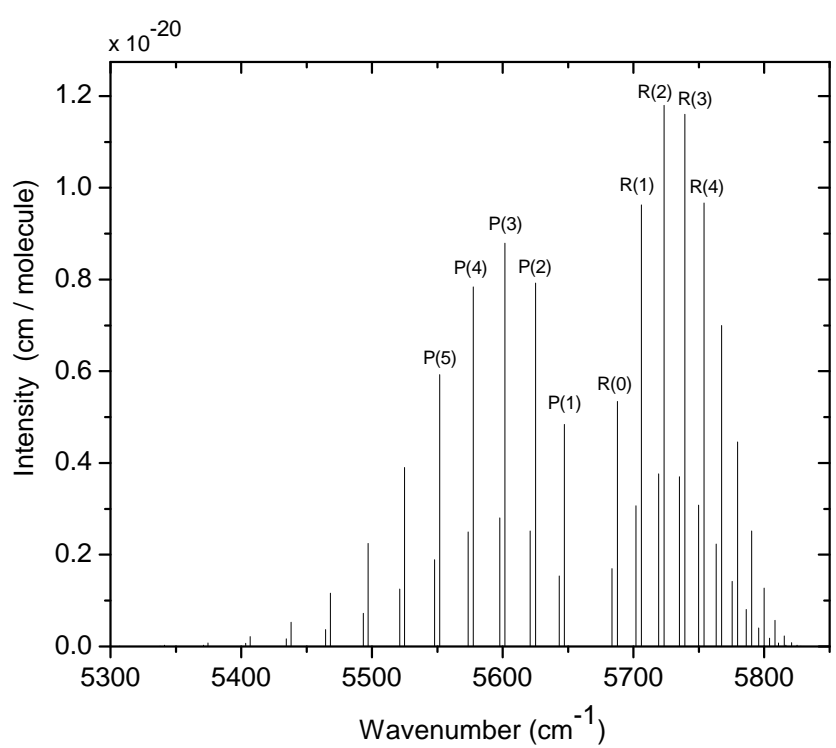

Fig. 1. Linestrengths of rotational lines of the 2-0 vibrational absorption band of $\mathrm{H}^{35} \mathrm{Cl}$ and $\mathrm{H}^{37} \mathrm{Cl}$ from HITRAN. The CRDS sensor uses the $\mathrm{R}(3)$ line of $\mathrm{H}^{35} \mathrm{Cl}$ at $5739.26 \mathrm{~cm}^{-1}$.

strength, its separation from other atmospheric absorbers, and its accessibility using available near-infrared (NIR) components. The (2-0) band corresponds to molecules changing from their initial vibrational level of $v^{\prime \prime}=0$ (i.e., vibrational ground state) to final level of $v^{\prime}=2$ as a photon is absorbed. We have labeled the first $5 \mathrm{P}$ - and R-branch transitions (absorption lines) in Fig. 1. There are two nearby lines for each transition corresponding to absorption by the two isotopologues $\mathrm{H}^{35} \mathrm{Cl}$ and $\mathrm{H}^{37} \mathrm{Cl}$. The absorption line strengths include the isotopic abundances $\left(0.758\right.$ for $\mathrm{H}^{35} \mathrm{Cl}$ and 0.242 for $\mathrm{H}^{37} \mathrm{Cl}$ ) so that measured concentrations correspond to the overall $\mathrm{HCl}$ population (i.e., both isotopologues). The targeted line has also been selected by other researchers for laser absorption measurements of $\mathrm{HCl}$ (Ortwein et al., 2010; De Rosa et al., 2001). Although our selected wavelength of $1742 \mathrm{~nm}$ is slightly outside the standard telecommunications bands, nearly all of the needed equipment (laser, fiber optics, mirrors, etc.) is available from telecom suppliers. The fundamental (1-0) vibrational band of $\mathrm{HCl}$, near $3.4 \mu \mathrm{m}$, has much greater line strengths and has been used in Herriott cell approaches, with lead salt lasers, discussed above. It is also possible to access this spectral region using differencefrequency generation (DFG) laser sources (Weibring et al., 2010) or interband cascade lasers, but these sources and associated components are more expensive and less commercially developed.

Separation from the absorption lines of other potential interfering molecules is critical to successful optical measurements. We have considered interferences due to expected ambient molecules, and their relevant isotopologues, including: $\mathrm{CH}_{4}, \mathrm{CO}, \mathrm{CO}_{2}, \mathrm{HCl}, \mathrm{H}_{2} \mathrm{O}, \mathrm{NO}$, and $\mathrm{N}_{2} \mathrm{O}$. As shown in 

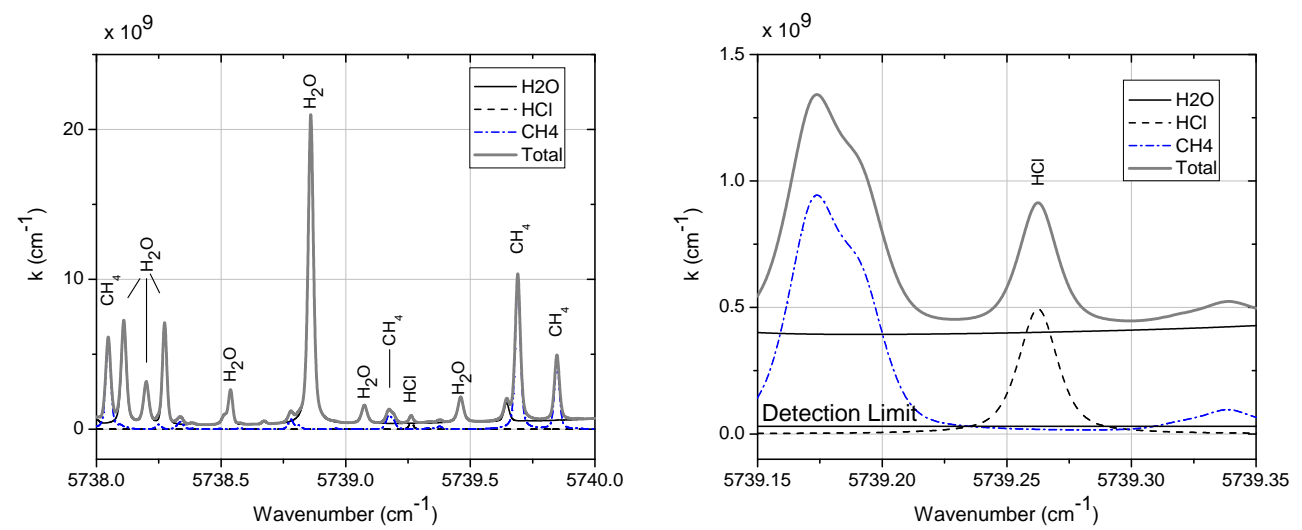

Fig. 2. Simulated absorption spectra in the vicinity of the targeted $\mathrm{HCl}$ absorption line. Simulated conditions are: $P=0.08$ bar, $T=295 \mathrm{~K}$, $\mathrm{HCl}=0.5 \mathrm{ppbv}, \mathrm{CH}_{4}=1.8 \mathrm{ppmv}, \mathrm{H}_{2} \mathrm{O}=0.013$ (50\% Relative Humidity). Left/Right: Zoomed out/in of $\mathrm{HCl}$ line.

Fig. 2, we have simulated the absorption spectra in the vicinity of the targeted $\mathrm{HCl}$ absorption line. The simulations use an $\mathrm{HCl}$ concentration of $500 \mathrm{pptv}$, and assume typical ambient species concentrations, spectral parameters from HITRAN, and standard expressions for thermal and collisional line broadening (Rothman et al., 2013). There is a tradeoff of operating pressure in the ring-down cell, and we have examined possible performance at difference pressures. Reducing the pressure tends to narrow the spectral absorption features and improve specificity, but at the cost of reduced signal amplitudes and, at sufficiently low pressure $(\sim 0.05$ bar $)$, can introduce operational challenges with the flow system. An operating cell pressure of 0.08 bar was found to be a reasonable compromise.

The $\mathrm{R}(3) \mathrm{H}^{35} \mathrm{Cl}$ linestrength was updated in the 2012 HITRAN database to $1.25 \times 10^{-20} \mathrm{~cm}_{\text {molecule }}{ }^{-1}$ from the work by Ortwein et al. (2010) Also, several additional water and methane lines were added in the spectral region near the targeted $\mathrm{HCl}$ line of interest. The spectra in Fig. 2 include these additional lines. The targeted $\mathrm{HCl}$ line is sufficiently isolated from the nearby methane lines to allow sensitive concentration measurements. A scan extent of $\sim 0.075 \mathrm{~cm}^{-1}$ allows the full $\mathrm{HCl}$ feature, with baseline on either side, to be recorded. The methane absorption only very weakly affects the flatness of the $\mathrm{HCl}$ baseline given that the methane contribution changes by only $\sim 2 \times 10^{-11} \mathrm{~cm}^{-1}$ over the scan extent.The near-infrared (NIR) 2-0 absorption band has an approximately 50 times smaller line strength than the infrared fundamental 1-0 band. However, the increased sensitivity afforded by CRDS, and the availability of NIR optical equipment, make the 2-0 band an attractive choice.

Figure 3 shows the schematic layout of the CRDS system. The light source is a distributed-feedback (DFB) diode laser (KELD1F5DAAA, NEL Lasers, Saddlebrook, NJ, USA) in a 14-pin butterfly package with a center wavelength of $1742 \mathrm{~nm}$, linewidth of a few $\mathrm{MHz}$, and $13 \mathrm{~mW}$ of output power through a single-mode fiber pigtail. Light from the laser is first sent through a $99 \%-1 \%$ fiber-optic beam splitter. The $99 \%$ leg is used as the main interrogating beam, while the weaker leg is used for the frequency calibration leg. During frequency calibration, the $1 \%$ output leg from the fiber splitter is sent through a low-finesse Fabry-Perot etalon (fused silica, $45 \mathrm{~mm}$ long, finesse $\sim 20$ ), and a photodiode (PDA10CS, Thorlabs, Newton, NJ, USA) monitors the etalon transmission signal. The relative frequency of the laser (as determined by the etalon transmission peaks) is plotted against the voltage sent to the laser controller (LDC-3714C, ILX Lightwave, Bozeman, Montana, USA) and a second order polynomial is fitted to it, which provides a relationship between relative laser frequency and controller voltage for subsequent use. This frequency determination procedure is done automatically in our custom LabVIEW software and takes only a few seconds. Owing to the high stability of the DFB laser, the calibration coefficients derived from the fit proved stable over months and have not yet been tested over longer time periods. In regular operation, the etalon is replaced with a $5.7 \mathrm{~cm}$ path length custom reference cell, which is a sealed glass vessel containing a high concentration of $\mathrm{HCl}(\sim 0.1 \%)$ in atmospheric pressure air. Since the reference cell is at atmospheric pressure, while the cavity is at $0.08 \mathrm{~atm}$, there is a $\sim 0.01 \mathrm{~cm}^{-1}$ difference in absorption wavenumber, which is small compared to the $\sim 0.08 \mathrm{~cm}^{-1}$ scan amplitude. As the instrument runs, the $1 \%$ leg of the beam splitter is sent through the reference cell, and the photodiode monitors the transmission. Due to the high concentration of $\mathrm{HCl}$ in the cell, a strong absorption feature is observed through a path length of only a few $\mathrm{cm}$. The sensor control software finds the peak of this absorption feature and centers the laser scan on the $\mathrm{HCl}$ spectral feature, thus ensuring any ambient temperature changes do not cause the laser wavelength to drift away from the desired spectral region.

The $99 \%$ output leg from the fiber splitter is first sent through an aspheric collimation lens (CFC-11X-C, $f=$ $11 \mathrm{~mm}$, Thorlabs, Newton, NJ, USA). The aspheric lens is 


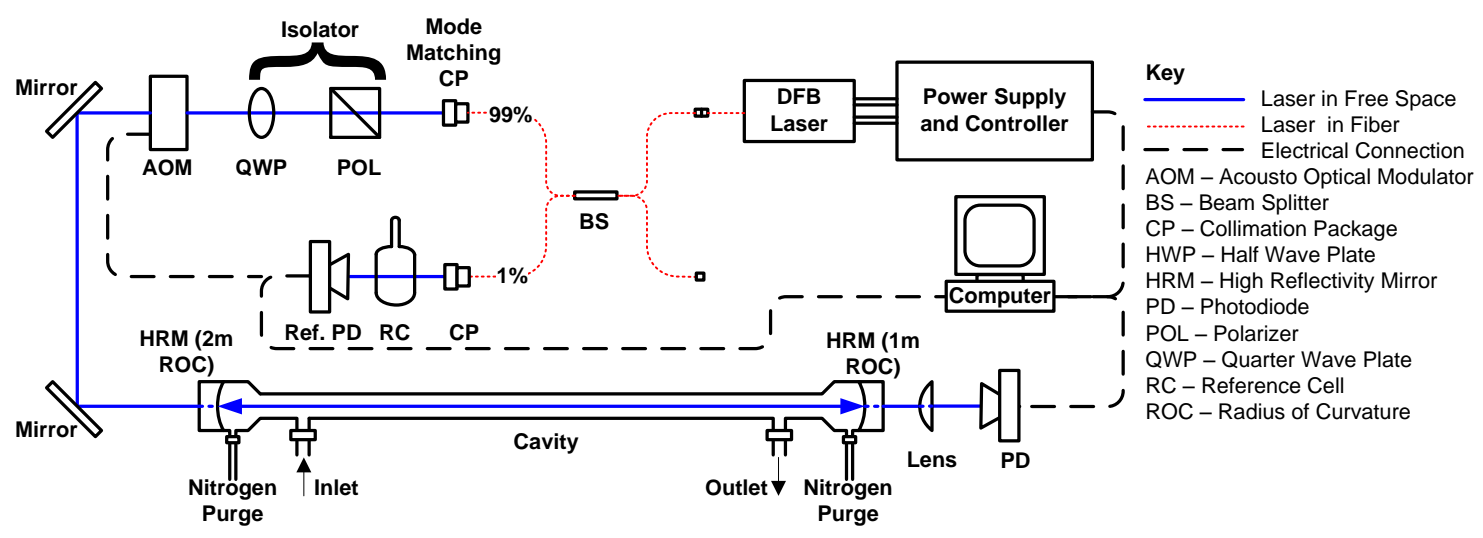

Fig. 3. Schematic of the optical components and data acquisition systems of the $\mathrm{HCl}$ sensor. The reference cell is used during normal operation, and is replaced with the Fabry-Perot etalon only during frequency calibration.

precisely positioned relative to the fiber beam-splitter output in order to spatially mode match the beam to the $\mathrm{TEM}_{0,0}$ mode of the cavity, which also requires proper separation of the cavity and lens (Kogelnik and Li, 1966). After the collimation package, a polarizer and quarter-wave plate are used in series as an optical isolator, blocking light reflected from the cavity from going back into the laser, which, even in small amounts, causes noticeable instabilities in the laser. The $20 \mathrm{~dB}$ isolator within the laser did not sufficiently extinguish the back reflection from the cavity. The last element before the high-finesse cavity is the acousto-optic modulator (AOM, ACM-402AA1, IntraAction, Bellwood, IL, USA). When the data acquisition (DAQ) system detects a resonance out of the optical cavity, the computer turns off the AOM, causing the incoming laser to be rapidly extinguished (time constant of $\sim 300 \mathrm{~ns}$ ). The optical cavity itself is constructed of two high-reflectivity dielectric mirrors (Advanced Thin Films, Boulder, CO, USA), with radii of curvature of $2 \mathrm{~m}$ and $1 \mathrm{~m}$, and a separation of $90 \mathrm{~cm}$. These radii were chosen to roughly minimize the needed mode-match distance. For these curvatures, the cavity is stable for lengths up to $1 \mathrm{~m}$, and between 2 and $3 \mathrm{~m}$. The mirror reflectivity was determined to be $R=99.9982 \%$ as measured from empty-cavity ringdown times of $\sim 170 \mu$ s, which was consistent with manufacturer specification.

Indium Gallium Arsenide (InGaAs) photodiodes are widely used for NIR detection, however, the responsivity of InGaAs diodes drops below $0.1 \mathrm{~A} \mathrm{~W}^{-1}$ at $1742 \mathrm{~nm}$ as compared to a peak of $1.1 \mathrm{~A} \mathrm{~W}^{-1}$ at $1550 \mathrm{~nm}$. Extended wavelength InGaAs diodes, with lower bandgap energies, provide higher responsivity farther into the IR, but the dark current also increases significantly. For detection of our main cavity beam, we employ an extended wavelength InGaAs photodiode (G8421-03, Hamamatsu, San Jose, CA, USA), which is soldered onto a transimpedance amplifier (341-4, Analog Modules, Longwood, FL, USA). The amplifier has an input capacitance matched to the photodiode, a gain adjusted to
$2 \times 10^{6} \mathrm{~V} / \mathrm{A}$, and a bandwidth of $2 \mathrm{MHz}$. The bandwidth is approximately 5 times larger than needed in order to not distort the ring-down signals. Using a detector with a higher bandwidth than required results in increased noise, as highfrequency detector dark noise is unnecessarily amplified. Other detector options are discussed in Sect. 4. The cavity detector voltage signal is digitized by a $2.5 \mathrm{MS} \mathrm{s}^{-1}$, 14-bit PCI multi-purpose DAQ card (PCI-6132, National Instruments, Austin, TX, USA), which also controls the AOM. A second DAQ card (PCIe-6321, National Instruments, Austin, TX, USA) is used to output the analog voltage signal to the laser controller, as well as to digitize the reference cell detector signal.

A custom LabVIEW program is used to control the instrument and to handle data acquisition and processing. First the software sends an analog voltage to the laser controller scanning the laser in a triangle wave between 5739.22 and $5739.30 \mathrm{~cm}^{-1}$ with a $1 \mathrm{~s}$ period (the analog output is converted from a 16-bit digital signal, which gives 520 wavelength steps over the scan range). When the photodetector signal out of the cavity exceeds a pre-determined threshold (indicative of the laser being in resonance with the cavity), the LabVIEW software turns off the AOM, digitizes the ringdown signal, and fits the data to an exponential function using an iterative nonlinear least squares fit seeded by a linear least-squares fit (Lehmann and Huang, 2009). Whenever a ring-down event is recorded, the relative laser frequency is calculated from the etalon calibration. The total DAQ system is capable of acquiring more than 200 ring downs per second, which is faster than needed, as the system is optically limited to $\sim 20$ per second. Further increasing the laser scan speed, and therefore the acquisition rate, decreases the amount of light transmitted through the cavity, reducing the overall detection sensitivity. Once the ring-down time is found, it is converted to an absorption coefficient, $k$, which still includes 


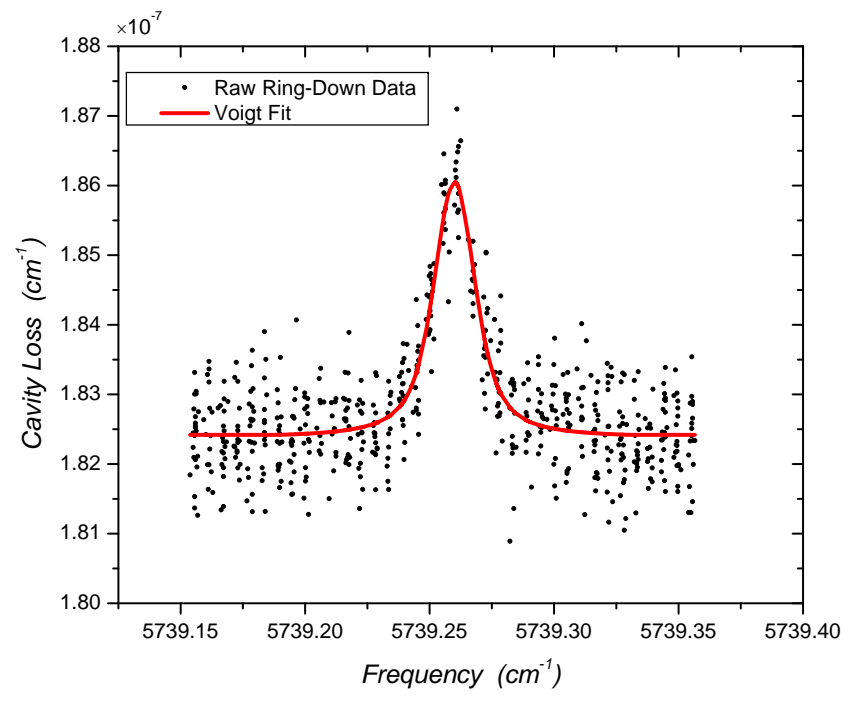

Fig. 4. Example plot of the measured cavity loss values versus frequency in the vicinity of the $\mathrm{HCl}$ absorption feature after $30 \mathrm{~s}$ of acquisition time. The red line is a Voigt profile fit to the $\sim 600$ data points. The non-zero baseline is due to the empty cavity loss. The measured $\mathrm{HCl}$ concentration in this case is $4.68 \mathrm{ppbv}$.

the empty-cavity loss, given by

$k=\frac{1}{c \tau}$,

where $c$ is the speed of light, and $\tau$ is the ring-down time. The LabVIEW software collects ring-down signals for a set amount of time (typically $30 \mathrm{~s}, \sim 600$ individual ring downs), termed the integration time, after which the spectrum of recorded absorption values are fit to a Voigt profile, as shown in Fig. 4. Note that Fig. 4 shows an absorption peak of $\mathrm{HCl}$ mixed with zero air. Therefore, there are no nearby methane lines, and the scan extent was made wider. For sampling of ambient air, the extent of the frequency scan is $0.075 \mathrm{~cm}^{-1}$, in order to capture sufficient baseline without methane interference. Curve fitting to a Voigt profile can be computationally expensive. To avoid computer downtime, a table of pre-computed Voigt profiles is used. Voigt and Lorentzian spectral widths are calculated from the known gas conditions inside the sampling cell and used to look up the numerical Voigt profile from the table. Interpolation is used to infer Voigt profile values for laser frequencies between tabulated values. The amplitude, offset (baseline), and center of these numerical values are then scaled to achieve a least-squares fit to the data, and ultimately find the area under the Voigt curve. The measured area under the spectral line, along with the pressure, temperature, and line strength, are used in conjunction with the ideal gas law and the Beer-Lambert law to find the ambient $\mathrm{HCl}$ mixing ratio, which is given by

$[\mathrm{HCl}]=10^{6} \frac{T k_{\mathrm{B}} A}{P S L_{\mathrm{s}}}$, where $T$ is the temperature of the intra-cavity gas in $\mathrm{K}, P$ is the pressure in $\mathrm{Pa}, k_{\mathrm{B}}$ is Boltzmann's constant in $\mathrm{J} \mathrm{K}^{-1}, A$ is the area under the spectral line in $\mathrm{cm}^{-1}$ (discussed below), $S$ is the line strength in cm molecule ${ }^{-1}$, and $L_{\mathrm{s}}$ is the sample path length in $\mathrm{cm}$. The area under the spectral line, $A$, is the integral Voigt profile fitted to the dimensionless cavity loss $\left(\frac{L}{c \tau}\right)$ over frequency in $\mathrm{cm}^{-1}$, where $L$ is the cavity length. For CRDS systems in which the interrogated sample fills the entire region between the mirrors, the sample path length is the same as the physical distance between the cavity mirrors. However, as can be seen in Fig. 3, the cavity inlet and outlet flows are connected over a shorter path than the mirror separation distance. A nitrogen purge flow rate of 0.4 standard liters per minute (sLpm) is introduced in the cavity at each mirror surface in order to prevent particles from contaminating the mirror surfaces, as well as to prevent $\mathrm{HCl}$ from potentially interacting with non-Teflon surfaces, where they would strongly adsorb (more details given below). To compensate for the diluted sample, a sample path length replaces the cavity length in Eq. (2) (Brown et al., 2000). To determine the sample path length, the laser wavelength was tuned to the nearby water absorption line in Fig. 2, and the area of this spectral line was found with the purge flow on and off. The cavity length (mirror separation) was multiplied by the ratio of these areas, yielding a sample path length of $86 \%$ of the cavity length (which nearly matches the length between the sample inlet and outlet ports).

Details of the flow system are shown in Fig. 5. As previously mentioned, the system is run at 0.08 bar to ensure separation between spectral features. A vacuum was pulled on the system by a dry scroll pump (IDP2B01, Varian), which provides $8 \mathrm{sLpm}$ (including the $0.4 \mathrm{sLpm}$ purge flow) of flow through the cavity. Cavity pressure and flow rate were regulated by a combination of two needle valves: a Teflon valve just after the intake and a metal valve on the bypass leg.

The system also employs a simple virtual impactor to remove large particles from the main sampling flow (Chen and Yeh, 1987). Not only are large particles in the sample flow threatening to the highly reflective mirror surfaces, but they can scatter or absorb intra-cavity light, increasing the variance in the ring-down time. It is strongly preferred not to use an in-line particulate filter owing to possible measurement artefacts associated with $\mathrm{HCl}$ condensation on to the filter, and aerosol loading and $\mathrm{pH}$-dependent acid-displacement reactions. Instead, the virtual impactor acts as a particle filter by requiring the flow to quickly turn 180 degrees before being routed to the cavity. The design requires the flow to be split into two legs as shown in Fig. 5. The main system inlet is the center orifice of a $3 / 8^{\prime \prime}$ NPT PFA tee fitting. A $\sim 1.5 \mathrm{~mm}$ inner diameter PFA tube, leading to the detection cavity, is inserted $5 \mathrm{~cm}$ into one side of the tee. The third side of the tee is connected to a $25 \mathrm{~W}$ pump (Air Supra HK-25L), which pulls $25 \mathrm{Lpm}$ of air through the fitting. Large particles, which cannot turn quickly enough, flow towards the impactor pump and not to the cavity. 


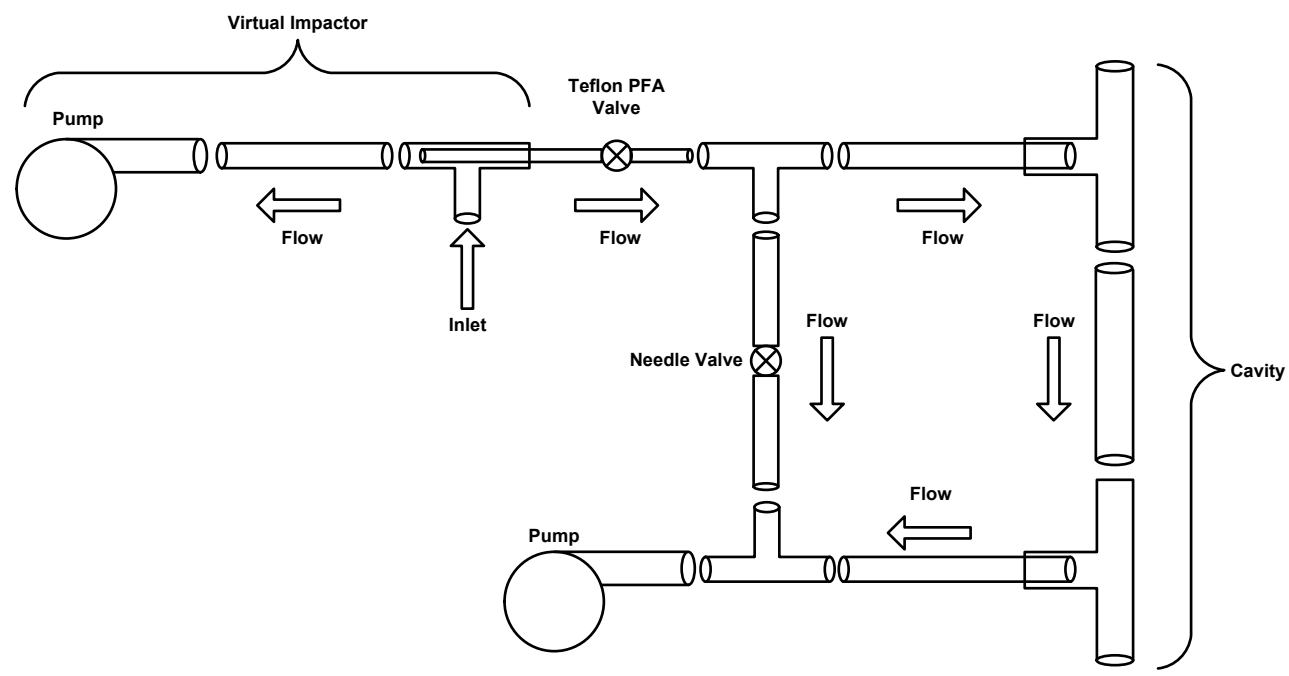

Fig. 5. Schematic diagram of the $\mathrm{HCl}$ sensor gas flow system. The virtual impactor, indicated on the left, serves to remove large particles from the main sampling flow. The optical cavity is indicated on the right.

Due to its very high aqueous solubility, $\mathrm{HCl}$ has a high propensity to adsorb to surfaces, which constrains the instrument design and limits the detection time response. The adsorption can be partially mitigated by reducing the surface area of the flow system and cavity, and by using Teflon components. Perfluoroalkoxy (PFA), a type of Teflon, was the fluoropolymer of choice because components can be injection molded from PFA resulting in less porous surfaces than other fluoropolymer pieces forged from a powder, such as polytetrafluoroethylene (PTFE). Additionally, the inlet and cavity tubing are heated to $60^{\circ} \mathrm{C}$, which causes surface desorption of the $\mathrm{HCl}$ to occur faster, and reduces the amount of moisture available to trap $\mathrm{HCl}$. In other instruments, it has been shown that even using short lengths of extruded nonporous fluoropolymer tubing will adsorb $\mathrm{HCl}$ resulting in an instrument response time of greater than $90 \mathrm{~s}$ (Roberts et al., 2010). The time response of the present instrument is discussed in Sect. 3.3.

\section{Sensor performance}

In this section, validation studies and performance metrics for the $\mathrm{HCl}$ sensor are discussed. The various subsections address the sensor sensitivity (to $\mathrm{HCl}$ concentration as well as base optical sensitivity), validation data from a calibrated source, sensor response time, initial field deployment, and potential improvements.

\subsection{Sensitivity and detection limit}

The detection limit of a CRDS sensor for measuring concentrations of trace atmospheric species depends on the instrument's optical precision as well as the spectroscopic relation between the optical absorption and species concentration. We first discuss the instrument's detection limits in terms of gas concentration measurements after which the optical sensitivity is discussed. While longer integration times generally lead to improved detection limits, eventually system drift dominates such that there is a finite, optimum, integration time. In order to find the ideal integration (averaging) time for the presented CRDS system, we performed an Allan Variance study on a time-sequence of concentration measurements using a modified method (Huang and Lehmann, 2010). The modified method yields a much smoother Allan Variance curve than the traditional two-sample variance method. Figure 6 (top plot) shows concentration data with the optical cavity purged with ultra-zero air (purity $\sim 99.9997 \%$ ). The minimum in the Allan Variance is $\sim 8 \mathrm{pptv}$ (bottom plot), which occurs at an optimal integration time of $\sim 15$ min. For shorter measurement times we find detection limits $(1 \sigma)$ of $10 \mathrm{pptv}$ after $5 \mathrm{~min}$ and infer $\sim 40 \mathrm{pptv}$ after $10 \mathrm{~s}$. These values compare favorably against the typical atmospheric abundances that the sensor is designed to measure (see Sect. 1.2). The detection limits of the present instrument is somewhat better than those of past work using MIR lasers and Herriot cells ( $\sim 100 \mathrm{pptv}$ in $30 \mathrm{~s}$, Scott et al., 1999) with the primary difference being that the current sensor has several orders of magnitude better optical sensitivity (owing to our use of CRDS versus multi-pass cells), but probes weaker lines (2-0 band as opposed to 1-0 band).

We have followed a similar approach to characterize the optical sensitivity of the instrument (independent of analyte). An Allan variance study of the ring-down times was also performed and is shown in Fig. 7. The minimum in the Allan Variance of $\sim 0.01 \mu$ s (bottom plot), which occurs at an optimal integration time of $\sim 30 \mathrm{~s}$, divided by the mean 


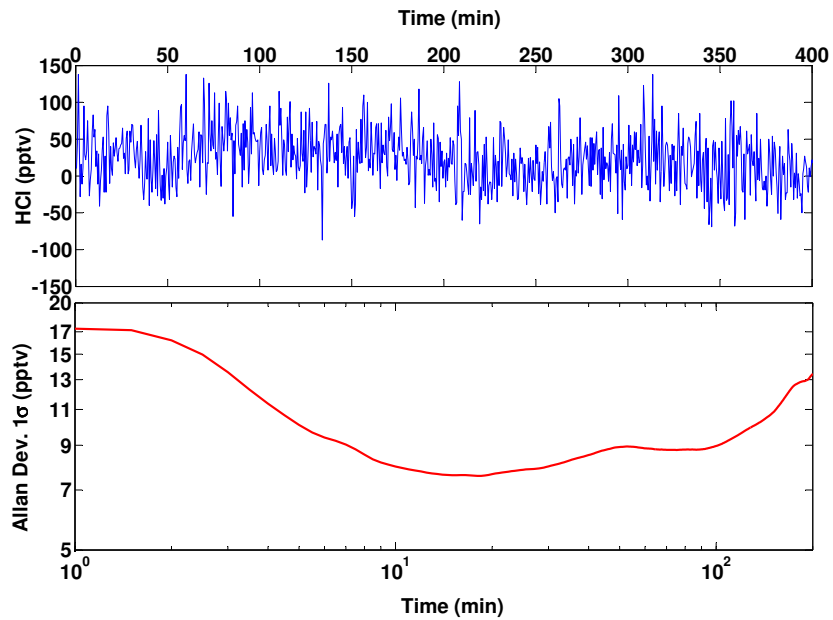

Fig. 6. Measured $\mathrm{HCl}$ concentration values (top) and their associated Allan Deviation curve (bottom) with the optical cavity purged with ultra-zero air. The measurement period was $30 \mathrm{~s}$.

ring-down time, gives $\left(\frac{\Delta \tau}{\tau}\right)_{\text {Min }}$ of $5.3 \times 10^{-5}$, where $\left(\frac{\Delta \tau}{\tau}\right)_{\text {Min }}$ is the minimum measurable fractional change in the ringdown time (typically limited by technical noise). Following standard expressions (Zalicki and Zare, 1995), and using $R=0.99982$ and $L_{\mathrm{s}}=77 \mathrm{~cm}$, results in an optical sensitivity $(1 \sigma)$ of $1.3 \times 10^{-11} \mathrm{~cm}^{-1}$ in $30 \mathrm{~s}\left(7.0 \times 10^{-11} \mathrm{~cm}^{-1} \mathrm{~Hz}^{-\frac{1}{2}}\right)$. This optical sensitivity compares favorably against those achieved by other cw-CRDS systems (Berden et al., 2000; Paldus and Kachanov, 2005). From the HITRAN spectral simulations discussed earlier, an optical sensitivity of $1.3 \times$ $10^{-11} \mathrm{~cm}^{-1}$ corresponds to a theoretical $\mathrm{HCl}$ detection limit of $\sim 11 \mathrm{pptv}$. This inferred concentration detection limit is a factor of $\sim 2-3$ better than that actually found for this instrument. The discrepancy is because, for actual concentration measurements, the laser must be scanned over the broadened spectral line to allow for baseline fitting and accommodation of laser drift. The concentration limit inferred from the ring downs would apply if the laser were fixed at a single frequency on the spectral line peak.

\section{2 $\mathrm{HCl}$ validation data}

We have performed tests with an $\mathrm{HCl}$ calibration source in order to validate the accuracy of the instrument. Such characterizations are particularly needed for gas phase $\mathrm{HCl}$ because it is a difficult molecule to sample due to adsorption (see end of Sect. 2). The validation source uses a permeation tube containing hydrochloric acid, which slowly diffuses through the Teflon tube wall. The tube emits gaseous $\mathrm{HCl}$ at a rate of $10 \pm 1 \mathrm{ng} \mathrm{min}^{-1}$ when temperature controlled at $55^{\circ} \mathrm{C}$. The emission rate was characterized by comparison with a $10 \mathrm{ppmv}$ gaseous $\mathrm{HCl}$ standard. The $10 \mathrm{ppmv}$ standard was cross checked by conversion to HONO and measurement by incoherent broadband cavity-enhanced absorption
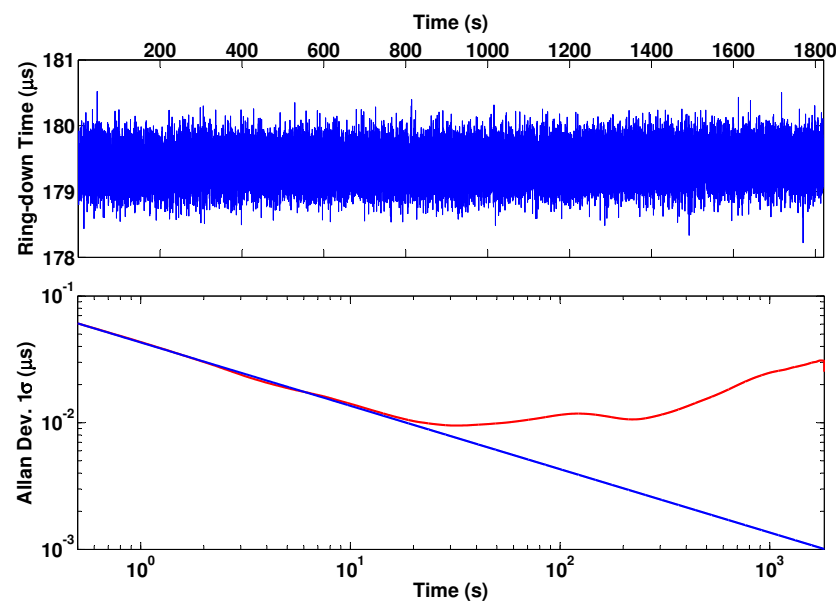

Fig. 7. (Top) Sample ring-down data when the optical cavity was purged with ultra-zero air. (Bottom) Modified Allan Deviation of the ring-down data (red solid line) as compared to the idealized data without drift, i.e., time $e^{-1 / 2}$ dependence (blue line). The average rate at which ring downs are acquired is $\sim 20 \mathrm{~Hz}$, however, it is not constant, as the computer simply triggers whenever a resonance is detected.

spectroscopy (Fiedler et al., 2003) and total $\mathrm{NO}_{\mathrm{y}}$ (Roberts et al., 2010). Ultra-pure zero air (Airgas, $99.9997 \%$ pure) flows over the permeation tube at a rate of $9.9 \mathrm{sccm}$, giving an $\mathrm{HCl}$ concentration of $630 \mathrm{ppbv}$. The flow from the permeation tube is further diluted by a few sLpm of zero air at a rate set by an adjustable mass flow controller, thereby allowing the final $\mathrm{HCl}$ concentration to be set. Finally, the calibration air is sent into the inlet of the system.

Figure 8 shows concentration data measured by the CRDS instrument plotted against the input concentration. A range of $\mathrm{HCl}$ concentrations, between 0.75 and $6.25 \mathrm{ppbv}$, from the calibration source were studied. Each plotted point is a $10 \mathrm{~min}$ average (corresponding to averaging 20 measurements each obtained over $30 \mathrm{~s}$ ), and the red line shows the ideal $1: 1$ correlation. The errors bars in the input concentrations are due to a $10 \%$ uncertainty in the calibration source, while errors bars on the measured concentration are taken as the $(1 \sigma)$ standard deviation in the measured values during the 10 min averaging time. We observe consistency of better than $10 \%$ between the expected and measured values, similar to that reported in past work using lead salt lasers and Herriot cells (Scott et al., 1999). Ideally, mixing ratios below $0.75 \mathrm{ppbv}$ would have also been tested. However, it is difficult to obtain calibration sources which provide such low concentrations.

\subsection{Response time}

A potential advantage of using optical approaches for $\mathrm{HCl}$ measurement is the ability to have relatively fast instrument response times. Of course, instrument temporal response also 


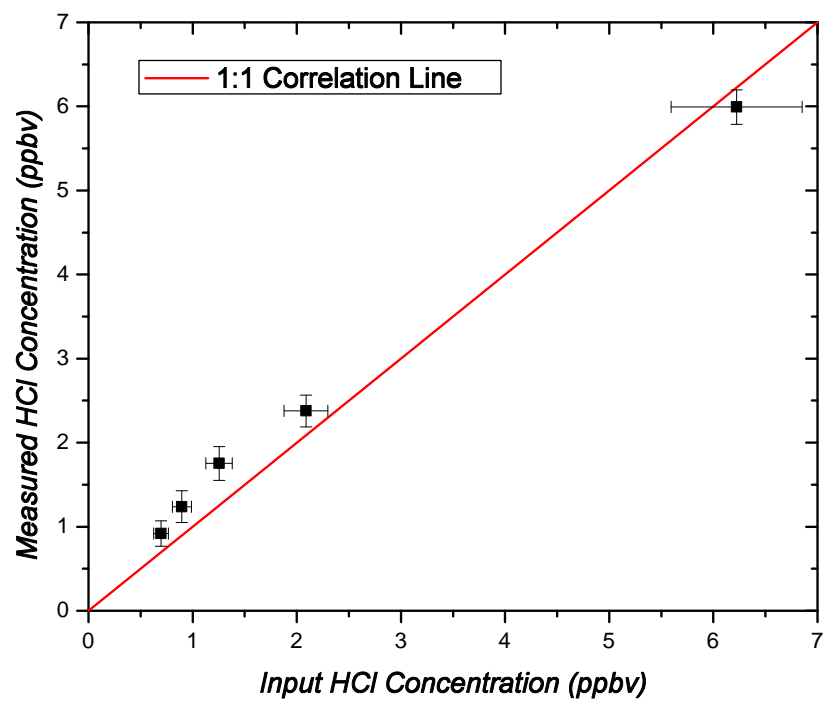

Fig. 8. $\mathrm{HCl}$ concentration measurements averaged for $10 \mathrm{~min}$ as compared to the concentration supplied to the inlet from the calibration system. The solid line shows the expected $1: 1$ correlation between the measured and input values.

determines utility for field campaigns, especially those using mobile platforms. Because $\mathrm{HCl}$ has high aqueous solubility and strongly adsorbs onto surfaces, the inlet design and sensor time response are particularly challenging. Past work has shown that designing a fast-response inlet and flow system for $\mathrm{HCl}$ is difficult and requires careful consideration of flowrates, materials, and geometry (Roberts et al., 2010).

Using a similar setup as that described in the above subsection (but with a different permeation tube), we characterized the response time for several inlet and flow-system designs. We provided step-changes in the input concentration and characterized the response time based on the time needed to reach $90 \%$ of the final settled value. Figure 9 shows an example of a time-sequence of raw ring-down times during a step change in $\mathrm{HCl}$ concentration (ppbv level) yielding a $90 \%$ settling time of $10 \mathrm{~s}$. Ring-down times at the $\mathrm{HCl}$ absorption peak center are used, as they are directly responsive to changes in $\mathrm{HCl}$ concentration. The step pictured in Fig. 9 corresponds to an approximate concentration change of $10 \mathrm{ppbv}$. Similar response times were found for both increases and decreases in concentration. The $\mathrm{HCl}$ settling time in our final design, which uses a PFA Teflon cavity of $6.4 \mathrm{~mm}$ inner diameter and flow rate of $8 \mathrm{sLpm}$, is consistently below $15 \mathrm{~s}$. The cavity was held at $60^{\circ} \mathrm{C}$ with resistive heaters. This response time is limited by gas adsorption effects since similar characterizations, based on changes in $\mathrm{CO}_{2}$ concentration (and using the spectrally close $\mathrm{CO}_{2}$ feature), yielded response times of $<1 \mathrm{~s}$ consistent with the transit time (residence time) of gas in our cavity.

A series of experiments were conducted to better understand the factors influencing the response time. In all cases,

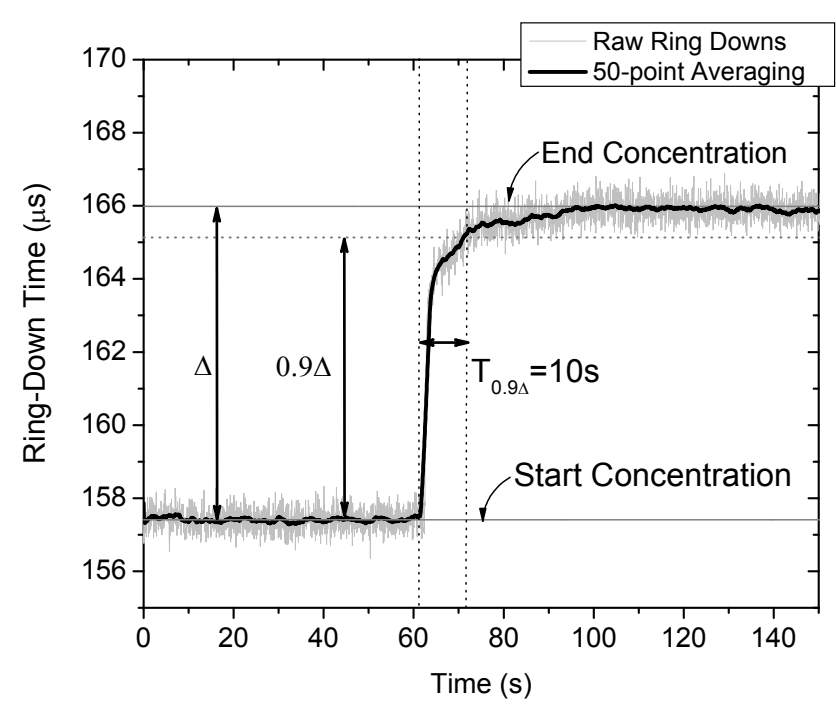

Fig. 9. Time sequence of ring-down signals (obtained with laser tuned near $\mathrm{HCl}$ peak) as the $\mathrm{HCl}$ input concentration was impulsively changed (at $T=60 \mathrm{~s}$ ). The instrument response time was found as $10 \mathrm{~s}$ (based on the time needed to capture $90 \%$ of the final change) and is representative of both step-up and step-down changes.

the optical cavity and inlet tubing were made from PFA Teflon owing to its low porosity. While keeping other conditions fixed, we studied response times for optical cavities of inner-diameters 9.5, 7.9, and $6.4 \mathrm{~mm}$ and found that the response time was fairly linear against diameter (i.e., cavity surface area). Significant reductions to even smaller diameters are not possible owing to the mode-matched beam dimensions within the cavity. We have also studied the response time for gas flow rates of 3, 4, 5, and $7 \mathrm{sLpm}$ through the system and found the response time scales as roughly inverse of the flow-rate. This finding is consistent with earlier work showing that the $\mathrm{HCl}$ measurement settling time can be related to the number of residence times of the gas in the sensor and that approximately 30-60 residence times are needed for $\mathrm{HCl}$ (Fried et al., 1984).

The time response shown in Fig. 9 is for dry air. It is possible that at higher relative humidity, the time response could be different due to a change in the affinity of the Teflon walls for $\mathrm{HCl}$. At the low pressure and high temperature operation of this instrument $\left(\sim 0.08 \mathrm{~atm}, 60^{\circ} \mathrm{C}\right)$, the effective relative humidity in the cavity is $1.6 \%$ even if the sampled ambient air has $100 \%$ relative humidity at $25^{\circ} \mathrm{C}$ and 1 atmosphere pressure. Thus we anticipate the cavity walls will remain essentially dry even under humid conditions.

\subsection{Field study demonstration}

The first field test of the present CRDS instrument was during the Nitrogen, Aerosol Composition and Halogens on a tall tower (NACHTT) campaign, in Weld County, Colorado 


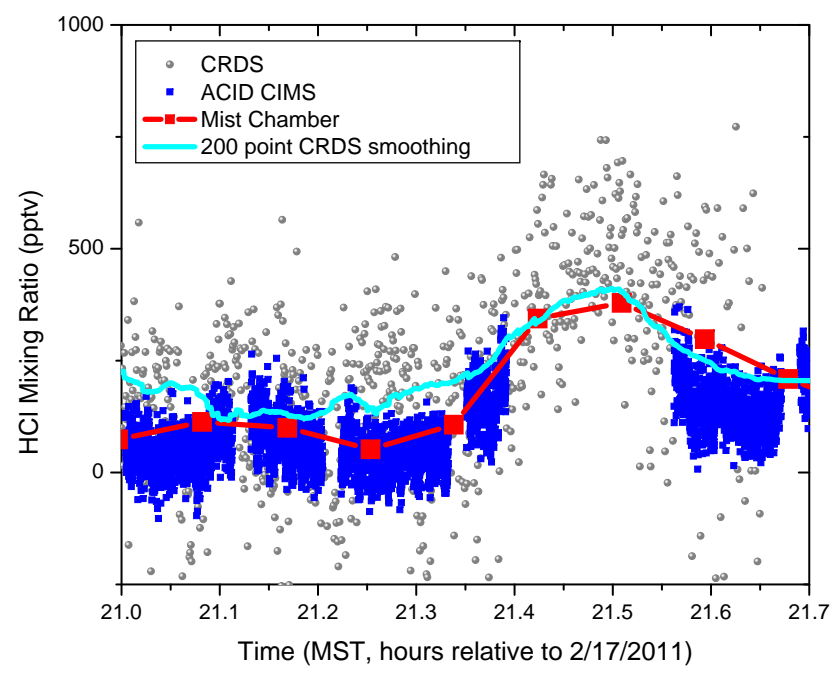

Fig. 10. $\mathrm{HCl}$ concentration values recorded by the CRDS, ACID CIMS, and mist chamber instruments during the NACHTT campaign. The time is Mountain Standard Time.

during early 2011 (Brown et al., 2013). Although the instrument was still early in its development, and not yet optimized for sensitivity or response time, the field campaign provided an opportunity to run our instrument side-by-side with two other instruments employing different $\mathrm{HCl}$ measurement methods. The first method being acid CIMS, (VandenBoer et al., 2011) and the second method being mist chamber ion-chromatography (Young et al., 2013).

Located within a box truck, the CRDS instrument collected air samples from the base of the Boulder Atmospheric Observatory, a $300 \mathrm{~m}$ research tower. The mist chamber ionchromatography instrument was also located at the tower base with an inlet $22 \mathrm{~m}$ a.g.l., while the acid CIMS instrument traveled in a carriage up and down the tower. The $\mathrm{HCl}$ CRDS instrument used its own inlet, that was a $\sim 1 \mathrm{~m}$ PTFE line heated to $60^{\circ} \mathrm{C}$. The inlet flow rate was $\sim 29 \mathrm{sLpm}$ ( $\sim 25 \mathrm{sLpm}$ virtual impactor and $\sim 4$ sLpm cavity flow). The time response of the inlet configuration used during the field study was not precisely measured, but was about a few minutes.

The acid CIMS instrument was placed within a carriage that traveled up and down a $300 \mathrm{~m}$ tall tower in order to make vertically resolved $\mathrm{HCl}$ measurements. For the comparison in Fig. 10, only $\mathrm{HCl}$ concentration values during which the tower carriage was at ground level were used. The acid CIMS instrument has a limit of detection of $25 \mathrm{pptv}$ ( $1 \sigma$, scaled from reported $2 \sigma$ value) and an inlet equilibration time of $>90 \mathrm{~s}$ for $\mathrm{HCl}$. The mist chamber ion-chromatography (IC) instrument was placed at ground level near the CRDS instrument. The IC instrument has a limit of detection of $\sim 20 \mathrm{pptv}$ ( $1 \sigma$, also scaled from reported $2 \sigma$ value). The measurement time of the IC instrument is much slower, typically many minutes.
$\mathrm{HCl}$ concentration measurements taken by the three $\mathrm{HCl}$ instruments are compared in Fig. 10. The sample dataset, taken around 21:30 MST on Day 21 (17 February 2011) of the study, shows agreement between the three instruments, including observation of a plume containing $\sim 400 \mathrm{pptv}$ of $\mathrm{HCl}$ within $\sim 50$ agreement. At the time of the NACHTT study, the optical precision of the sensor was a factor of $\sim 5$ poorer than the current instrument, since many improvements were made subsequently. Because of this, we do not perform more detailed analysis.

\subsection{Instrument improvements}

In the remainder of this section, possible instrument modifications are briefly discussed. While these modifications may improve performance, we note that the current limit of detection is below what is needed for most field study needs. From an optical point of view, several improvements could be considered. First, a detector and amplifier combination with lower bandwidth $(\sim 400 \mathrm{kHz})$ would allow faithful measurement of the ring-down signal while lowering the adverse effects of high-frequency noise. The detector bandwidth could arguably be dropped further, for example, to $40 \mathrm{kHz}$, without distortion of the $\sim 180 \mu$ s ring downs. However, the dynamic range of the sensor would be limited, and the sensor may not accurately measure large $\mathrm{HCl}$ concentrations. The detector bandwidth and data sampling rate could be investigated in more detail, perhaps following Lehmann and Huang (2009). Second, a thermo-electrically cooled photodiode could be used to reduce the detector dark noise. Further, improved sensitivity can be obtained from more complicated CRDS schemes, though at the cost of increased hardware cost and complexity. One such example is to use a PoundDrever-Hall locked cavity similar to Spence et al. (2000) in which the laser and cavity frequencies are locked together such that higher ring-down acquisition rates of several $\mathrm{kHz}$ are possible. While increasing the rate at which ring-downs are acquired may not improve the limit of detection, it will allow the system to reach the limit of detection faster, which can be very useful for mobile field instruments.

From a packaging point of view, a more compact and robust design would be attractive for studies on aircrafts or boats. The overall dimensions of the CRDS instrument are $\sim 1.4 \times 1.2 \times 0.55 \mathrm{~m}$. Currently, a commercial optical breadboard is used to mount all of the optical components while a straightforward improvement would be to use a smaller dedicated breadboard that could be mounted on a spring-damping system for improved vibration isolation. Further, the data acquisition computer uses a relatively large PCI DAQ card, which could be replaced with a smaller and faster PCIe card. Issues related to the sticky gas adsorption can also be further investigated, with the goal of reducing the settling time, such as possible sample line passivation procedures (Keene et al., 1993). 
Finally, as can be seen in Fig. 2, the current system can readily detect nearby spectral absorption lines due to water and methane. While these lines are not optimum selections for these molecules, they could be detected concurrently with $\mathrm{HCl}$ with detection limits of $\sim 5 \mathrm{ppmv}$ and $\sim 2 \mathrm{ppbv}$ for water and methane respectively (based on scaling the $\mathrm{HCl}$ data by relative linestrengths). Additionally, by changing only the laser, cavity mirrors, and quarter-wave plate, other NIR absorbing molecules such as $\mathrm{CO}, \mathrm{CO}_{2}$, and $\mathrm{H}_{2} \mathrm{~S}$ would be readily measurable.

\section{Conclusions}

This contribution has described the design and characterization of an $\mathrm{HCl}$ sensor utilizing cw-CRDS. Relatively lowcost NIR components, similar to those used in telecommunications, were used to create the instrument. The instrument features $\mathrm{HCl}$ detection limits of $<20$ pptv in 1 min with optimum integration times of $\sim 15 \mathrm{~min}$ to achieve the best possible detection limit of 8 pptv. Calibration studies have shown good agreement with expected values (accuracy better than $\sim 10 \%$ ). We also find (90\% settling) response times of $<15 \mathrm{~s}$ for step-changes in input concentration.

The instrument performance metrics should meet the needs for many measurement campaigns and compares favorably against other instruments. For example, there is interest in deploying such sensors on future aircraft campaigns. With a $10 \mathrm{~s}$ measurement time, the sensor provides a limit of detection $(1 \sigma)$ of $\sim 40 \mathrm{pptv}$, which should be sufficient for $\mathrm{HCl}$ measurements near coastal areas. Assuming a typical aircraft cruising speed of $100 \mathrm{~m} \mathrm{~s}^{-1}, \mathrm{HCl}$ concentrations could be made with a $\sim 1 \mathrm{~km}$ spatial resolution.

The two most common isotopologues of $\mathrm{HCl}$ are $\mathrm{H}^{35} \mathrm{Cl}$ (75.76\%) and $\mathrm{H}^{37} \mathrm{Cl}(24.23 \%)$. The presented instrument directly measures the mixing ratio of $\mathrm{H}^{35} \mathrm{Cl}$, from which the overall $\mathrm{HCl}$ concentration is inferred. The $\mathrm{R}(4)$ line of $\mathrm{H}^{37} \mathrm{Cl}$ can also be measured without spectral interference. Thus, sensitive ambient measurements of the two strongest $\mathrm{HCl}$ isotopologues should be possible. Isotopologues containing deuterium are much less abundant but may be measurable under laboratory conditions using high concentrations of $\mathrm{HCl}$.

Relative to the past work with Herriott cells, the present instrument does not require $\mathrm{LN}_{2}$ cooled lead salt lasers or detectors (though DFG lasers, with Herriot cells, may also be of future interest). And, for measurements of sticky gases, the larger surface area of Herriot cells (as well as off-axis cavity enhanced cells) is challenging for time response unless much higher flow rates (larger pumps) are used. While there are two commercial CRDS instruments available for $\mathrm{HCl}$, their details are not in the open literature, which can be particularly problematic for use in field studies where it may be needed to reconfigure instrument(s). For example, inlet changes may be made to achieve tradeoffs in flowrate, response time etc. A prototype of the present instrument was demonstrated in a field campaign, showing consistency against other $\mathrm{HCl}$ instruments.

Acknowledgements. The authors acknowledge A. A. P. Pszenny and W. C. Keene for their permission to present data from their mist chamber ion-chromatography instrument. Finally, the authors also acknowledge funding support from the National Science Foundation (Award Number: 0948015).

Edited by: F. Stroh

\section{References}

Achard, V., De Maziére, M., Camy-Peyret, C., Karcher, F., and Lippens, C.: Spaceborne measurements of the upper stratospheric $\mathrm{HCl}$ vertical distribution in early 1992 and the trend in total stratospheric chlorine since 1985, J. Geophys. Res. Atmos., 102, 8985-8990, doi:10.1029/97JD00004, 1997.

Allan, W., Struthers, H., and Lowe, D. C.: Methane carbon isotope effects caused by atomic chlorine in the marine boundary layer: Global model results compared with Southern Hemisphere measurements, J. Geophys. Res., 112, D04306, doi:10.1029/2006JD007,369, 2007.

Berden, G. and Engeln, R. (Eds.): Cavity Ring-Down Spectroscopy: Techniques and Applications, Wiley-Blackwell, 2009.

Berden, G., Peeters, R., and Meijer, G.: Cavity ring-down spectroscopy: Experimental schemes and applications, Int. Rev. Phys. Chem., 19, 565-607, doi:10.1080/014423500750040627, 2000.

Bjoroey, O., Haugholt, K. H., and Jaeger, T.: Diode laser spectroscopy of gaseous HCl, Quantum Electronics, 26, 1090-1092, 1996.

Brown, S. S., Wilson, R. W., and Ravishankara, A. R.: Absolute Intensities for Third and Fourth Overtone Absorptions in $\mathrm{HNO}_{3}$ and $\mathrm{H}_{2} \mathrm{O}_{2}$ Measured by Cavity Ring Down Spectroscopy, J. Phys. Chem. A, 104, 4976-4983, doi:10.1021/jp000439d, 2000.

Brown, S. S., Thornton, J. A., Keene, W. C., Pszenny, A. A. P., Sive, B. C., Dubé, W. P., Wagner, N. L., Young, C. J., Riedel, T. P., Roberts, J. M., VandenBoer, T. C., Bahreini, R., Öztürk, F., Middlebrook, A. M., Kim, S., Hübler, G., and Wolfe, D. E.: Nitrogen, Aerosol Composition and Halogens on a Tall Tower (NACHTT): Overview of a wintertime air chemistry field study in the Front Range urban corridor of Colorado, J. Geophys. Res. Atmos., 18, 8067-8085, doi:10.1002/jgrd.50537, 2013.

Busch, K. and Busch, M.: Cavity-Ringdown Spectroscopy (ACS Symposium Series 720), Oxford University Press, 1999.

Chen, B. and Yeh, H.: An improved virtual impactor: Design and performance, J. Aerosol Sci., 18, 203-214, doi:10.1016/00218502(87)90056-5, 1987.

De Rosa, M., Nardini, C., Piccolo, C., Corsi, C., and D'Amato, F.: Pressure broadening and shift of transitions of the first overtone of $\mathrm{HCl}$, Appl. Phys. B, 72, 245-248, doi:10.1007/s003400000449, 2001.

Dudek, J. B., Tarsa, P. B., Velasquez, A., Wladyslawski, M., Rabinowitz, P., and Lehmann, K. K.: Trace Moisture Detection Using Continuous-Wave Cavity Ring-Down Spectroscopy, Anal. Chem., 75, 4599-4605, doi:10.1021/ac0343073, 2003. 
Fiedler, S. E., Hese, A., and Ruth, A. A.: Incoherent broad-band cavity-enhanced absorption spectroscopy, Chemical Phys. Lett., 371, 284-294, doi:10.1016/S0009-2614(03)00263-X, 2003.

Fried, A., Sams, R., and Berg, W. W.: Application of tunable diode laser absorption for trace stratospheric measurements of HCI: laboratory results, Appl. Opt., 23, 1867-1880, doi:10.1364/AO.23.001867, 1984.

Gagliardi, G. and Loock, H. (Eds.): Cavity-Enhanced Spectroscopy and Sensing, Springer Series in Optical Sciences, 2014.

Graedel, T. E. and Keene, W. C.: Tropospheric budget of reactive chlorine, Global Biogeochem. Cy., 9, 47-77, 1995.

He, Y. and Orr, B.: Rapidly swept, continuous-wave cavity ringdown spectroscopy with optical heterodyne detection: singleand multi-wavelength sensing of gases, Appl. Phys. B, 75, 267280, doi:10.1007/s00340-002-0983-8, 2002.

Huang, H. and Lehmann, K. K.: Long-term stability in continuous wave cavity ringdown spectroscopy experiments, Appl. Opt., 49, 1378-1387, doi:10.1364/AO.49.001378, 2010.

Jobson, B. T., Niki, H., Yokouchi, Y., Bottenheim, J., Hopper, F., and Leaitch, R.: Measurements of $\mathrm{C}_{2}-\mathrm{C}_{6}$ hydrocarbons during the Polar Sunrise1992 Experiment: Evidence for $\mathrm{Cl}$ atom and Br atom chemistry, J. Geophys. Res. Atmos., 99, 25355-25368, doi:10.1029/94JD01243, 1994.

Keene, W. C., Maben, J. R., Pszenny, A. A. P., and Galloway, J. N.: Measurement Technique For Inorganic Chlorine Gases In The Marine Boundary-Layer, Environ. Sci. Technol., 27, 866-874, 1993.

Keene, W. C., Khalil, M. A. K., Erickson, D. J., McCulloch, A., Graedel, T. E., Lobert, J. M., Aucott, M. L., Gong, S. L., Harper, D. B., Kleiman, G., Midgley, P., Moore, R. M., Seuzaret, C., Sturges, W. T., Benkovitz, C. M., Koropalov, V., Barrie, L. A., and Li, Y. F.: Composite global emissions of reactive chlorine from anthropogenic and natural sources: Reactive Chlorine Emissions Inventory, J. Geophys. Res.-Atmos., 104, 8429-8440, 1999.

Keene, W., Stutz, J., Pszenny, A. A. P., Maben, J. R., Fischer, E. V., Smith, A. M., von Glasow, R., Pechtl, S., Sive, B. C., and Varner, R. K.: Inorganic chlorine in coastal New England air during summer, J. Geophys. Res., 112, D10S12, doi:10.1029/2006JD007689, 2007.

Kim, S., Huey, L. G., Stickel, R. E., Pierce, R. B., Chen, G., Avery, M. A., Dibb, J. E., Diskin, G. S., Sachse, G. W., McNaughton, C. S., Clarke, A. D., Anderson, B. E., and Blake, D. R.: Airborne measurements of $\mathrm{HCl}$ from the marine boundary layer to the lower stratosphere over the North Pacific Ocean during INTEX-B, Atmos. Chem. Phys. Discuss., 8, 3563-3595, doi:10.5194/acpd-8-3563-2008, 2008.

Knipping, E. M. and Dabdub, D.: Impact of Chlorine Emissions from Sea-Salt Aerosol on Coastal Urban Ozone, Environ. Sci. Technol., 37, 275-284, 2003.

Kogelnik, H. and Li, T.: Laser Beams and Resonators, Appl. Opt., 5, 1550-1567, doi:10.1364/AO.5.001550, 1966.

Lehmann, K.: Ring-down cavity spectroscopy cell using continuous wave excitation for trace species detection, 1996.

Lehmann, K. and Huang, H.: Frontiers of Molecular Spectroscopy, Elsevier, 2009.

Los Gatos Research: available at: www.lgrinc.com, last access: 11 July 2013.
Maben, J. R., Keene, W. C., Pszenny, A. A. P., and Galloway, J. N.: Volatile inorganic $\mathrm{Cl}$ in surface air over eastern North America, Geophys. Res. Lett., 22, 3513-3516, 1995.

Marcy, T. P., Fahey, D. W., Gao, R. S., Popp, P. J., Richard, E. C., Thompson, T. L., Rosenlof, K. H., Ray, E. A., Salawitch, R. J., Atherton, C. S., Bergmann, D. J., Ridley, B. A., Weinheimer, A. J., Loewenstein, M., Weinstock, E. M., and Mahoney, M. J.: Quantifying Stratospheric Ozone in the Upper Troposphere with in Situ Measurements of HCl, Science, 304, 261-263, 2004.

McCulloch, A., Aucott, M. L., Benkovitz, C. M., Graedel, T. E., Kleiman, G., Midgley, P. M., and Li, Y.-F.: Global emissions of hydrogen chloride and chloromethane from coal combustion, incineration and industrial activities: Reactive Chlorine Emissions Inventory, J. Geophys. Res. Atmos., 104, 8391-8403, doi:10.1029/1999JD900025, 1999.

Ortwein, P., Woiwode, W., Wagner, S., Gisi, M., and Ebert, V.: Laser-based measurements of line strength, self- and pressurebroadening coefficients of the $\mathrm{H}_{35} \mathrm{Cl} \mathrm{R}(3)$ absorption line in the first overtone region for pressures up to $1 \mathrm{MPa}$, Appl. Phys. B, 100, 341-347, doi:10.1007/s00340-009-3862-8, 2010.

Paldus, B. and Kachanov, A.: An historical overview of cavity enhanced methods, Can. J. Phys., 83, 975-999, 2005.

Platt, U., Allen, W., and Lowe, D.: Hemispheric average $\mathrm{Cl}$ atom concentration from ${ }^{13} \mathrm{C} /{ }^{12} \mathrm{C}$ ratios in atmospheric methane, Atmos. Chem. Phys., 4, 2393-2399, doi:10.5194/acp-4-2393-2004, 2004.

Pszenny, A. A. P., Moldanová, J., Keene, W. C., Sander, R., Maben, J. R., Martinez, M., Crutzen, P. J., Perner, D., and Prinn, R. G.: Halogen cycling and aerosol $\mathrm{pH}$ in the Hawaiian marine boundary layer, Atmos. Chem. Phys., 4, 147-168, doi:10.5194/acp-4147-2004, 2004

Roberts, J. M., Veres, P., Warneke, C., Neuman, J. A., Washenfelder, R. A., Brown, S. S., Baasandorj, M., Burkholder, J. B., Burling, I. R., Johnson, T. J., Yokelson, R. J., and de Gouw, J.: Measurement of HONO, HNCO, and other inorganic acids by negative-ion proton-transfer chemical-ionization mass spectrometry (NI-PT-CIMS): application to biomass burning emissions, Atmos. Meas. Tech., 3, 981-990, doi:10.5194/amt-3-981-2010, 2010.

Romanini, D., Kachanov, A., Sadeghi, N., and Stoeckel, F.: CW cavity ring down spectroscopy, Chemical Phys. Lett., 264, 316322, doi:10.1016/S0009-2614(96)01351-6, 1997.

Rothman, L., Gordon, I., Babikov, Y., Barbe, A., Benner, D. C., Bernath, P., Birk, M., Bizzocchi, L., Boudon, V., Brown, L., Campargue, A., Chance, K., Cohen, E., Coudert, L., Devi, V., Drouin, B., Fayt, A., Flaud, J.-M., Gamache, R., Harrison, J., Hartmann, J.-M., Hill, C., Hodges, J., Jacquemart, D., Jolly, A., Lamouroux, J., Roy, R. L., Li, G., Long, D., Lyulin, O., Mackie, C., Massie, S., Mikhailenko, S., Muller, H., Naumenko, O., Nikitin, A., Orphal, J., Perevalov, V., Perrin, A., Polovtseva, E., Richard, C., Smith, M., Starikova, E., Sung, K., Tashkun, S., Tennyson, J., Toon, G., Tyuterev, V., and Wagner, G.: The $\{\mathrm{HI}-$ TRAN2012\} molecular spectroscopic database, J. Quant. Spectr. Radiat. Tran., 130, 4-50, doi:10.1016/j.jqsrt.2013.07.002, 2013.

Scheuer, E., Talbot, R. W., Dibb, J. E., Seid, G. K., DeBell, L., and Lefer, B.: Seasonal distributions of fine aerosol sulfate in the North American Arctic basin during TOPSE, J. Geophys. Res., 108, 8370, doi:10.1029/2001JD001364, 2003. 
Scott, D. C., Herman, R. L., Webster, C. R., May, R. D., Flesch, G. J., and Moyer, E. J.: Airborne Laser Infrared Absorption Spectrometer (ALIAS-II) for in situ atmospheric measurements of $\mathrm{N}_{2} \mathrm{O}, \mathrm{CH}_{4}, \mathrm{CO}, \mathrm{HCl}$, and $\mathrm{NO}_{2}$ from balloon or remotely piloted aircraft platforms, Appl. Opt., 38, 4609-4622, 1999.

Simpson, W. R., von Glasow, R., Riedel, K., Anderson, P., Ariya, P., Bottenheim, J., Burrows, J., Carpenter, L. J., Frieß, U., Goodsite, M. E., Heard, D., Hutterli, M., Jacobi, H.-W., Kaleschke, L., Neff, B., Plane, J., Platt, U., Richter, A., Roscoe, H., Sander, R., Shepson, P., Sodeau, J., Steffen, A., Wagner, T., and Wolff, E.: Halogens and their role in polar boundary-layer ozone depletion, Atmos. Chem. Phys., 7, 4375-4418, doi:10.5194/acp-74375-2007, 2007.

Solomon, S.: Stratospheric ozone depletion: A review of concepts and history, Rev. Geophys., 37, 275-316, 1999.

Spence, T. G., Harb, C. C., Paldus, B. A., Zare, R. N., Willke, B., and Byer, R. L.: A laser-locked cavity ring-down spectrometer employing an analog detection scheme, Rev. Sci. Instr., 71, 347353, doi:10.1063/1.1150206, 2000.

Tanaka, P. L., Oldfield, S., Neece, J. D., Mullins, C. B., and Allen, D. T.: Anthropogenic Sources of Chlorine and Ozone Formation in Urban Atmospheres, Environ. Sci. Technol., 34, 4470-4473, 2000.

Tiger Optics: available at: www.tigeroptics.com, last access: 11 July 2013.

VandenBoer, T. C., Wagner, N., Young, C. J., Dubé, B., Riedel, T. P., Bahreini, R., Öztürk, F., Warneke, C., De Gouw, J. A., Keene, W. C., Pszenny, A., Thornton, J. A., Wolfe, D. E., Brown, S. S., Middlebrook, A. M., and Roberts, J. M.: Vertical profiles of HONO during NACHTT 2011: Relative importance of heterogeneous production on aerosol versus the ground surface, AGU Fall Meeting Abstracts, p. F421, 2011.
Veres, P., Roberts, J. M., Warneke, C., Welsh-Bon, D., Zahniser, M., Herndon, S., Fall, R., and de Gouw, J.: Development of negative-ion proton-transfer chemical-ionization mass spectrometry (NI-PT-CIMS) for the measurement of gas-phase organic acids in the atmosphere, Int. J. Mass Spectr., 274, 48-55, doi:10.1016/j.ijms.2008.04.032, 2008.

Vogt, R., Crutzen, P. J., and Sander, R.: A mechanism for halogen release from sea-salt aerosol in the remote marine boundary layer, Nature, 383, 327-329, 1996.

Webster, C. R., May, R. D., Trimble, C. A., Chave, R. G., and Kendall, J.: Aircraft (ER-2) laser infrared absorption spectrometer (ALIAS) for in-situ stratospheric measurements of $\mathrm{HCI}, \mathrm{N}_{2} \mathrm{O}$, $\mathrm{CH}_{4}, \mathrm{NO}_{2}$, and $\mathrm{HNO}_{3}$, Appl. Opt., 33, 454-472, 1994.

Weibring, P., Richter, D., Walega, J. G., Rippe, L., and Fried, A.: Difference frequency generation spectrometer for simultaneous multispecies detection, Opt. Express, 18, 27670-27681, doi:10.1364/OE.18.027670, 2010.

Young, A. H., Keene, W. C., Pszenny, A. A. P., Sander, R., Thornton, J. A., Riedel, T. P., and Maben, J. R.: Phase partitioning of soluble trace gases with size-resolved aerosols in near-surface continental air over northern Colorado, USA, during winter, J. Geophysi. Res., 118, 2169-8996, doi:10.1002/jgrd.50655, 2013.

Zalicki, P. and Zare, R.: Cavity ring-down spectroscopy for quantitative absorption measurements, J. Chem. Phys., 102, 2708$2717,1995$. 